\title{
Uso da técnica de incrustação de insetos em resina como ferramenta didática para o ensino aprendizagem de biologia
}

Use of the insect encrustation technique in resin as a didactic tool for teaching and learning biology

Uso de la técnica de incrustación de insectos en resina como herramienta didáctica para la enseñanza y el aprendizaje de la biología

Recebido: 23/08/2021 | Revisado: 28/08/2021 | Aceito: 01/09/2021 | Publicado: 04/09/2021

Juliana Cristina dos Santos
ORCID: https://orcid.org/0000-0001-8009-7874
Instituto Federal de Educação, Ciência e Tecnologia do Sul de Minas Gerais, Brasil
E-mail: juliana.santos@ @uz.ifsuldeminas.edu.br
Gabriel Martins Moraes
ORCID: https://orcid.org/0000-0001-6780-6357
E-mail: gabrielmm213@gmail.com
Instituto Federal de Educação, Ciência e Tecnologia do Sul de Minas Gerais, Brasil
Guilherme Cândido de Souza Martins
ORCID: https:///orcid.org/0000-0002-0447-1761
E-mail: guilherme.candidosm @gmail.com
Douglas Maciel Carboni
Instituto Federal de Educação, Ciência e Tecnologia do Sul de Minas Gerais, Brasil
ORCID: https://orcid.org/0000-0002-7575-1090
E-mail: douglasoestebio @ gmail.com
Flavio Adriano Bastos
Instituto Federal de Educação, Ciência e Tecnologia de Santa Catarina, Brasil
Instituto Federal de Educação, Ciência e Tecnologia do Sul de Minas Gerais, Brasil
E-mail: flavio.bastos@ifsuldeminas.edu.br

\section{Resumo}

Os materiais fixados em polímeros são cada vez mais utilizados como ferramentas didáticas, devido a sua resistência, praticidade, facilidade de manuseio e aproximação com o objeto real de estudo, permitindo a compreensão dos aspectos morfológicos externos dos espécimes. Diante disso, verificamos a efetividade do método, através da técnica de incrustação de insetos, no processo de ensino-aprendizagem de discentes do terceiro ano do Ensino Médio. Inicialmente, aplicou-se um questionário, avaliando o conhecimento prévio dos alunos sobre a morfologia externa de exemplares de insetos. Em seguida, ministrou-se uma aula com os materiais incrustados, permitindo a manipulação e a visualização dos exemplares. Por fim, os discentes responderam ao questionário inicial novamente, verificando e validando o processo. Os dados obtidos indicam que as incrustações de insetos contribuíram para a compreensão das estruturas morfológicas externas. Portanto, se utilizada pelos docentes como ferramenta didática pode atuar efetivamente no processo de ensino-aprendizagem dos discentes.

Palavras-chave: Ensino; Artrópode; Educação; Metodologia ativa.

\begin{abstract}
Polymer fixed materials are increasingly used as instructional models, due to its strength, practicality, ease of handling and resemblance to the real object of study, allowing the understanding of the external morphological aspects of the specimens. Therefore, we verified the effectiveness of the method, through the technique of incrustation of arthropods, in the teaching-learning process of third-year high school students. Initially, a questionnaire was applied, evaluating the students' prior knowledge, on the external morphology of arthropod specimens. Then, a class was given with the models, allowing the manipulation and visualization of the copies. Finally, the students answered the initial questionnaire again, verifying and validating the process. The data obtained were transformed into percentage and presented in graphs, indicating that the models contributed to the understanding of arthropod structures. Therefore, this technique, if used by teachers, acts effectively in the teaching-learning process of students.
\end{abstract}

Keywords: Teaching; Arthropod; Education; Active methodology.

\section{Resumen}

Los materiales fijados en polímeros se utilizan cada vez más como modelos didácticos, debido a su resistencia, practicidad, facilidad de manejo y semejanza con el objeto real, permitiendo la comprensión de los aspectos morfológicos externos de los especímenes. Ante esto, verificamos la efectividad del método, a través de la técnica de 
incrustación de artrópodos, en el proceso de enseñanza-aprendizaje de los estudiantes de tercer año de secundaria. Inicialmente, se aplicó un cuestionario, evaluando el conocimiento previo de los alumnos sobre la morfología externa de ejemplares de artrópodos. Enseguida, se impartió una clase con los modelos, permitiendo la manipulación y la visualización de los ejemplares. Finalmente, los estudiantes respondieron nuevamente al cuestionario original, verificando y validando el proceso. Los datos obtenidos, fueron transformados en porcentaje y presentados en gráficos, indicando que los modelos han contribuido a la comprensión de las estructuras de los artrópodos. Por lo tanto, esa técnica, si utilizada por los docentes, actúa efectivamente en el proceso de enseñanza-aprendizaje de los discentes.

Palabras clave: Enseñanza; Artrópodos; Educación; Metodología activa.

\section{Introdução}

No ato de educar, os professores precisam ser criativos e inovadores, para cativar seus alunos, visto que, ao longo das décadas, ocorreram transformações significativas em diversas áreas, inclusive aquelas que impactaram profundamente a educação. O método tradicional de ensino é um modelo deficiente, não contempla mais as necessidades dos discentes e não abrange a totalidade do processo de ensino-aprendizagem (Paiva et al., 2016). Os discentes não aceitam mais um modelo autoritário e uniforme de aprender, já não bastando apenas memorização de informações para efetivar o processo. Devido a isso, é importante priorizar um envolvimento maior dos estudantes (Moran et al., 2015).

Uma maneira eficaz de ministrar as aulas na atualidade, é introduzir novas metodologias ativas de aprendizagem e inovadoras em sala de aula, técnicas que proporcionam o foco no protagonismo dos estudantes, tirando sua postura passiva, e que favoreçam a motivação e promovam a autonomia dos mesmos (Diesel et al., 2017, Santos et al., 2021). Além disso, são estratégias que chamam a atenção dos alunos e despertam o interesse, tornam as aulas menos rotineiras, mais atrativas, dinâmicas e participativas, contribuindo de maneira eficiente para que os conhecimentos sejam construídos de forma colaborativa. As metodologias ativas são uma atualização para ensinar, respeitando os saberes primários dos alunos e que trazem diversos benefícios (Paiva et al., 2016).

O uso de ferramentas didáticas são uma alternativa, que inserem a metodologia ativa de aprendizagem no ambiente escolar, combinam materiais e comunicações escritos, orais e visuais, para alcançar os objetivos pretendidos e permitem diálogo, integrando estudo e lazer, enquanto os discentes aprendem de maneira mais ampla e profunda, pela descoberta, pesquisa e observação (Berbel, 2011).

Neste contexto, coleções didáticas de insetos são de grande importância para o aprendizado de alunos, seja no ensino fundamental, médio ou superior. Existem diversas técnicas de preservação de artrópodes, dependendo do tamanho, estágio de desenvolvimento e estrutura corporal do organismo (Capanaga et al., 2013, p. 1). A falta de cuidado por parte dos estudantes em relação a materiais biológicos apresenta-se como um grande problema.

Em coleções entomológicas convencionais por exemplo, estruturas corpóreas frágeis como antenas, pernas e asas são facilmente danificadas, principalmente quando o manipulador do material não tem consciência de sua importância científica e, por isso, não toma os devidos cuidados para preservá-lo (Capanaga et al., 2013, p. 1).

Neste sentido, cada vez mais, é necessário o uso de inovações didáticas no ensino de Ciências e Biologia nas escolas. Essas inovações são consideradas um meio de buscar novas soluções nas dificuldades do processo de ensino-aprendizagem. Tais soluções se concretizam com estratégias que buscam a interação dos alunos com a Biologia e com o tema tratado de forma divertida e interativa (Amorim, 2013). Dessa forma, o método de preservação em resina permite que os caracteres utilizados para diferenciar os principais grupos taxonômicos dos artrópodes possam ser visualizados pelos estudantes. Essa estratégia de ensino é de grande valia, já que, nem todas as épocas do ano são possíveis obter exemplares de artrópodes para realização de aulas práticas. 
Com a técnica de incrustação de insetos, há uma redução do esforço de coletas constantes de espécimes para reposição de material, permitindo ao estudante maior facilidade de manuseio e de realizar uma análise detalhada das características do espécime em consecutivas aulas práticas sem danificá-lo (Capanaga et al., 2013). Além disso, essas incrustações não só permitem o reconhecimento das diferentes espécies pelos alunos, bem como podem relacionar o exemplar coletado com a função chave que o indivíduo desempenha nos ecossistemas, contribuindo ainda mais para o aprendizado dos alunos em sala de aula.

Desta forma, a técnica de incrustação de insetos em resina visa disponibilizar um material permanente para o manuseio dos alunos, possibilitando o aprendizado criativo, dinâmico e interativo. Portanto, objetivou-se com este estudo analisar o conhecimento prévio dos alunos do Ensino Médio do Colégio Estadual Dr. Guilherme Jose Missen, sobre o Filo Arthropoda e avaliar se a técnica de incrustação foi significativa no processo de ensino aprendizado dos alunos.

Baseado nisso, materiais didáticos de insetos incrustados foram inseridos na aula ministrada do presente estudo na disciplina de Biologia, como um facilitador do aprendizado dos discentes sobre o conteúdo referente ao Filo Arthropoda, com enfoque na Classe Insecta, já que, os insetos são os animais mais abundantes e diversos encontrados na terra (Bednaski, 2013).

\section{Metodologia}

Este trabalho foi realizado no Instituto Federal de Santa Catarina - Câmpus São Miguel do Oeste com os discentes do Ensino Médio matutino e noturno dos terceiros anos da Escola Estadual Dr. Guilherme Jose Missen, totalizando 24 discentes. Estes participaram apenas da etapa de aplicação dos questionários e aula sobre morfologia externa de insetos.

Primeiramente, foi realizada uma coleta de insetos em campo. Após os espécimes coletados, foram transfixados com alfinetes em placas de isopor e acondicionadas em estufa de secagem a $45^{\circ} \mathrm{C}$ por 24 horas. Decorrido este período, iniciou-se o processo de preparo da resina (polímero). A técnica de incrustação de insetos em resina foi adaptada conforme metodologia de Souza Junior et al., 2017. Para isso, utilizou-se para cada $100 \mathrm{~mL}$ de resina cristal de baixa viscosidade, 15 gotas do catalisador, produto facilmente encontrado em lojas virtuais. A resina foi inserida em um copo de medida de $500 \mathrm{~mL}$ de capacidade, logo após, adicionou-se o catalisador à solução. Agitou-se com cuidado, a fim de evitar a formação de bolhas de ar.

Em seguida, ocorreu o preparo dos moldes de silicone em que os insetos seriam acondicionados e foi adicionado uma camada da solução preparada anteriormente (resina + catalisador) de espessura de 0,5 a $1 \mathrm{~cm}$, com o intuito de formar uma base onde o espécime seria acondicionado. Após uma hora mantidos em temperatura ambiente $\left(25{ }^{\circ} \mathrm{C}\right.$ e Ura $\left.70 \pm 5 \%\right)$, a camada inicialmente aplicada, endureceu. Desta forma, introduziu o exemplar a ser incrustado, fixando-o nessa base com auxílio de uma pinça. Depois que o artrópode foi centralizado no molde, aguardou-se 24 horas até que o mesmo estivesse bem fixado. Decorrido este período, realizou-se a deposição de novas camadas de resina acrescida de catalisador na mesma concentração descrita anteriormente.

Os moldes com os respectivos espécimes foram mantidos a temperatura ambiente $\left(25{ }^{\circ} \mathrm{C}\right.$ e Ura de $70 \pm 5 \%$ por 48 horas), para secagem, que ocorreu por aproximadamente 10 dias. Após a secagem, foi realizado o lixamento e polimento dos exemplares incrustados. Para este propósito, foram utilizadas lixas de gramaturas 80, 120, 150, 180, 220, 320, 400, 600, 1200 e 1500, iniciando sempre com a mais áspera, reduzindo sequencialmente. Após o lixamento, as peças receberam polimento, para isso utilizou-se cera automotiva $\mathrm{n}^{\circ} 2$ e pano macio para limpar a peça e dar o acabamento final (Figura 1). 
Figura 1. Materiais didáticos de artrópodes incrustados, preparados com resina cristal de baixa viscosidade e catalisador utilizados para o processo de ensino-aprendizado na disciplina de biologia.

\section{A - Borboleta; B - Louva-deus; C - Gafanhoto; D - Libélula}
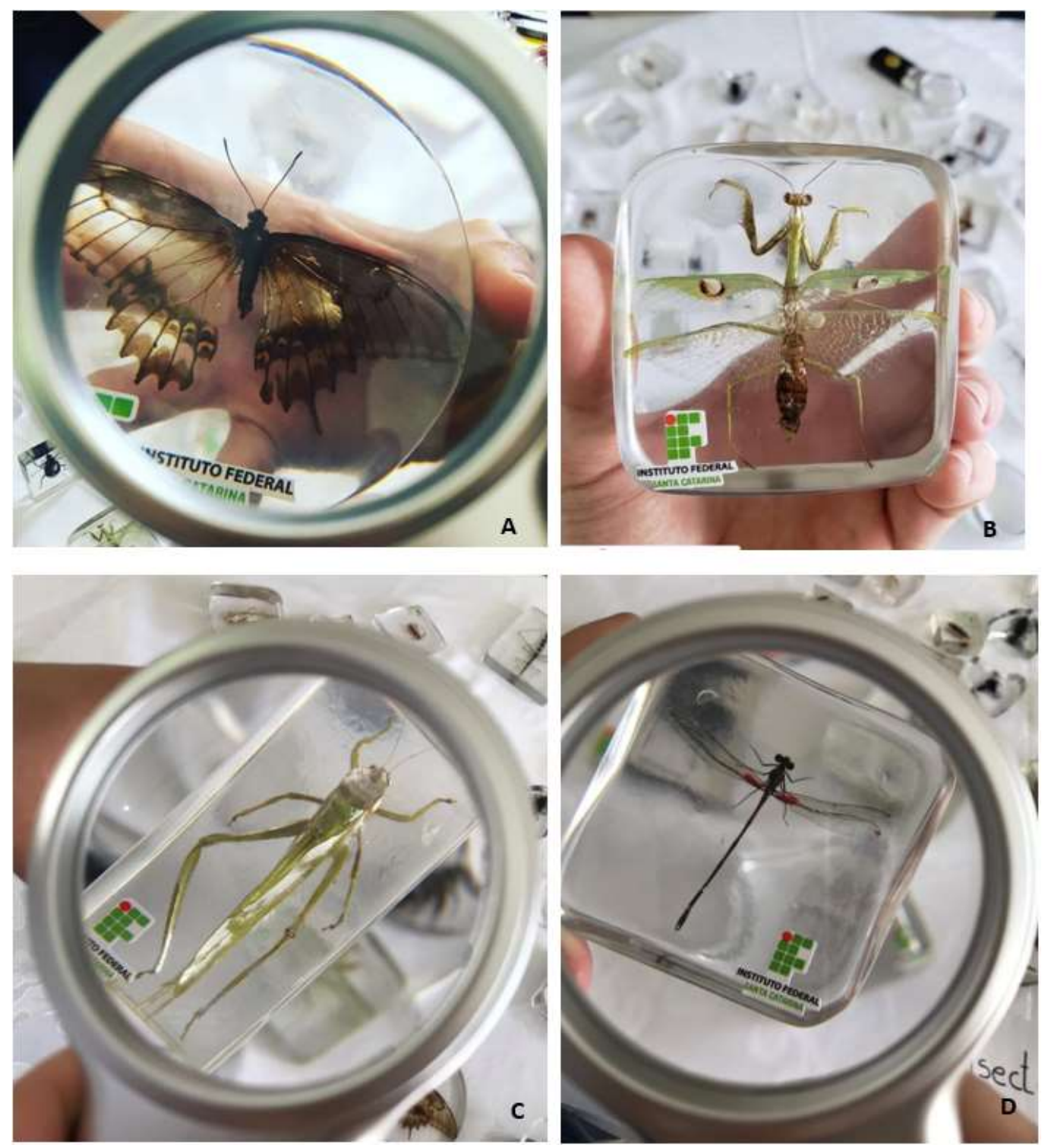

Fonte: Compilação dos autores produzidas antes da aula.

Para avaliar e valorizar o conhecimento prévio dos discentes, aplicou-se um questionário sobre as principais características morfológicas externas dos insetos, Filo Arthropoda, aos alunos do Ensino Médio da Escola Estadual Dr. Guilherme Jose Missen. Para este fim, os discentes responderam a um questionário disponibilizado (Quadro 1). 
Quadro 1. Questionário sobre o Filo Arthropoda e Classe Insecta realizadas aos estudantes do terceiro ano do Ensino Médio da Escola Estadual Dr. Guilherme Jose Missen, antes e após a utilização dos insetos incrustados em resina:

\section{Questões gerais sobre o Filo Arthropoda}

1- Qual o significado do Filo Arthropoda? Cite exemplos desse Filo.

2- O corpo dos artrópodes é constituído de um endo ou exoesqueleto? Quais são as principais funções?

3- Os artrópodes apresentam crescimento contínuo como nos vertebrados?

( ) $\operatorname{sim}$ ( ) não. Justifique sua resposta

\section{Questões específicas sobre a Classe Insecta}

1- Entre as classificações de artrópodes encontram-se os insetos. A respeito da segmentação corporal desses indivíduos pode-se afirmar que a divisão de seus corpos está correta em:

a- Cefalotórax e tronco b-Cefalotórax e abdome c- Cabeça, tórax e abdome d- Cabeça e tronco

2- Os insetos possuem antenas?

( ) não ( ) sim. Quantas e qual a função?

3- As asas e pernas dos insetos ficam acopladas em qual segmento corpóreo do inseto?

a- cabeça b- tórax c- abdome d - cefalotórax e- tronco

4- Os insetos possuem quantos pares de pernas?

( ) 1 par ( ) 2 pares ( ) 3 pares ( ) 4 pares

5- Quantas asas possui um inseto? Qual a função das asas nos insetos?

( ) não possui asas ( ) 1 par de asas funcionais ( ) 2 pares de asas funcionais ( ) todas as afirmativas corretas

6- Alguns insetos apresentam estilos e/ou cercos localizados no final do abdome, qual a sua função, respectivamente.

7- Os insetos apresentam espiráculos localizados no tórax e/ou abdome?

( ) não ( ) Sim. Qual a função dos mesmos?

Fonte: Dados da Pesquisa dos autores.

Após a coleta dos dados iniciais, foi ministrada uma aula expositiva dialogada, utilizando como recurso didático o projetor multimídia, as peças incrustadas e lupas manuais para a melhor visualização de estruturas. Ao final da aula, foi aplicado novamente o questionário para verificar a evolução do aprendizado dos alunos (Figura 2). 
Figura 2. Materiais didáticos sendo utilizados pelos discentes do Ensino Médio da Escola Estadual Dr. Guilherme Jose Missen.
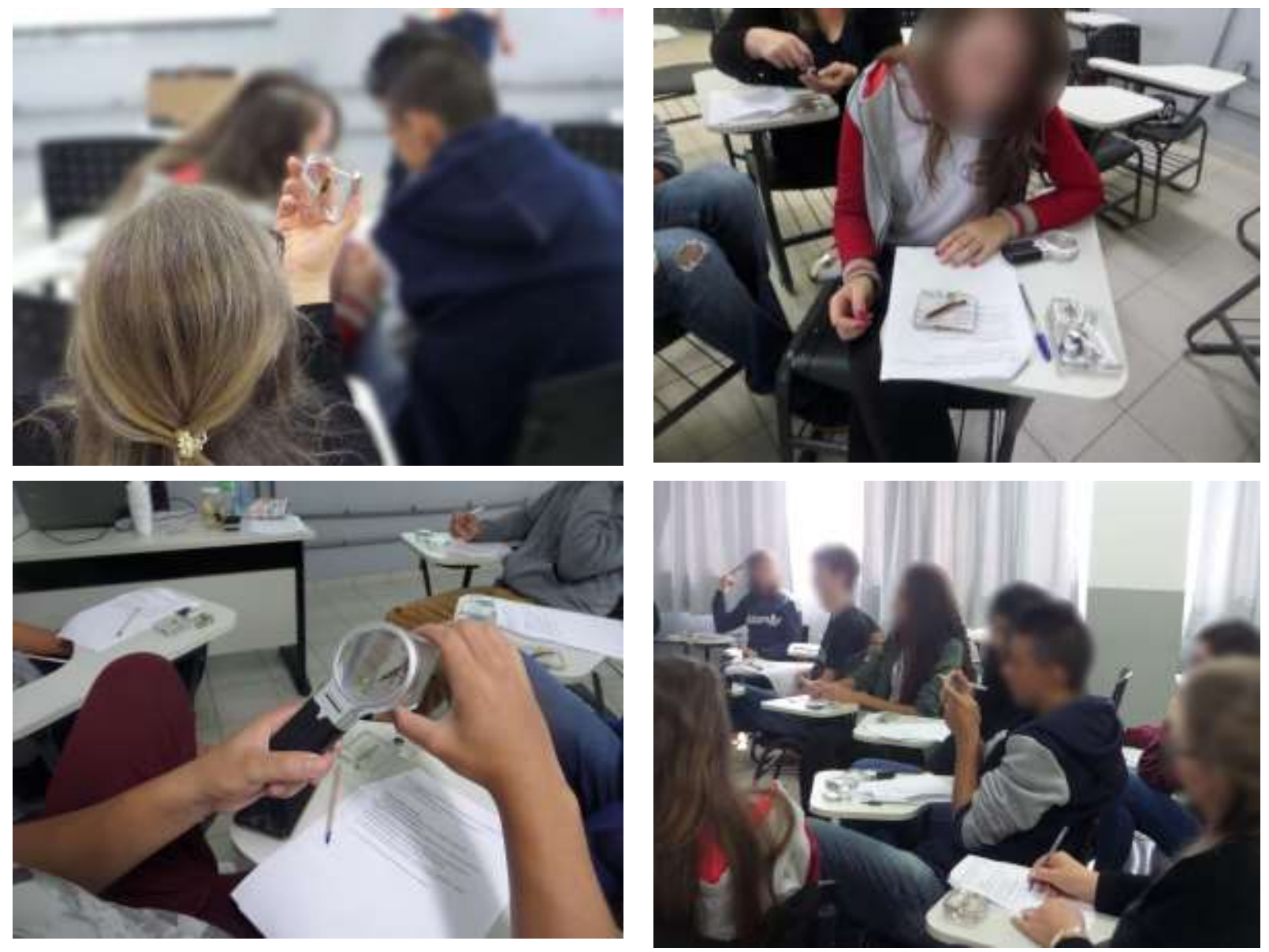

Fonte: Compilação dos autores produzidas durante a aula.

\section{Resultados e Discussão}

O Filo Arthropoda exibe uma rica biodiversidade animal, com várias linhas evolutivas de sucesso adaptativo e uma grande diversidade de formas e tamanhos. Estes apresentam grande importância ecológica, pois desempenham os mais variados papéis nas cadeias alimentares (Brusca et al., 2018). Os artrópodes exercem forte impacto sobre a economia e saúde humana. Alguns são parasitas do ser humano e de outros animais, tais como piolhos, pulgas e carrapatos; outros são vetores de doenças, como o mosquito da febre amarela, malária e dengue. Muitas espécies de ácaros, gafanhotos, formigas e moscas são pragas agrícolas. Outros atuam como agentes polinizadores, como abelhas, mamangavas, borboletas, sendo imprescindíveis para a produção de alimentos e matéria prima, como seda, mel e cera (Catani et al., 2016; Fujihara et al., 2011).

Devido a importância que este filo representa, perguntou-se aos discentes qual o significado do Filo Arthropoda e quais são os principais representantes desse filo. Ao analisar o pré-questionário, evidenciou-se que os discentes previamente não recordavam o termo ou seus principais representantes. Dos 24 entrevistados, apenas um mencionou " $E$ um Filo de animais invertebrados que apresentam exoesqueleto rígido". Após a aula, os alunos entenderam o significado do termo Arthropoda, do grego árthron = "articulado" e podós = "pé", ou seja, esses animais possuem como atributo pernas articuladas. As extremidades articuladas formam eficientes sistemas de alavancas e executam as mais diversas funções, tais como salto, corrida, escavação, natação, preensão, trituração de alimentos, inoculação de veneno e cópula (Silva et al., 2016). Na aula, os discentes puderam manipular os materiais incrustados, tais como abelhas, besouros, louva-a-deus, gafanhotos, esperanças, baratas, entre outros. 
Uma vez que os discentes tenham entendido o significado do filo, foram questionados sobre o tegumento dos artrópodes, se este é constituído de um endo ou exoesqueleto e quais as suas principais funções. Ao analisar o conhecimento prévio dos alunos, evidenciou-se na análise do pré-questionário que $91 \%$ dos entrevistados, em um primeiro momento, não souberam responder a essa questão (Figura 3). No entanto, $8 \%$ dos alunos mencionaram que o corpo dos artrópodes é constituído de um exoesqueleto e tem como principal função, proteção. Após a aula e análise dos exemplares incrustados, os alunos descreveram no pós-questionário que o corpo dos artrópodes é constituído por um exoesqueleto (100\% dos entrevistados) e desempenha variadas funções, tais como: "proteção contra os predadores", "evita a desidratação" e "funciona como uma carapaça protetora".

Figura 3. Resposta dos alunos sobre a composição do tegumento dos artrópodes.

\section{O corpo dos artrópodes é constituido de um endo ou exoesqueleto?}

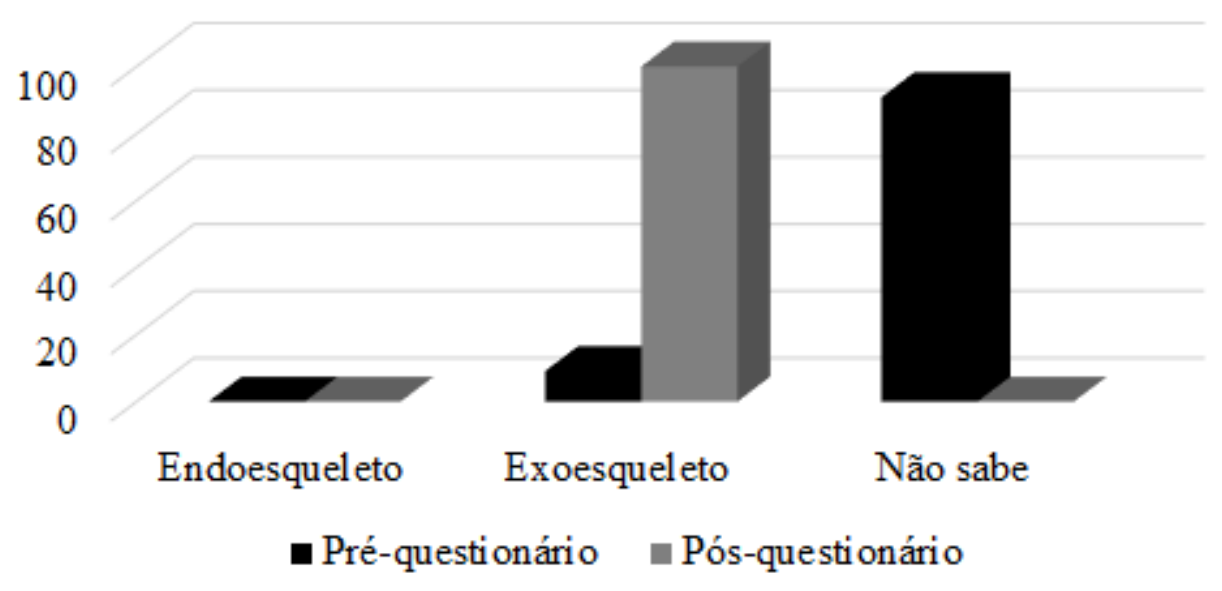

Fonte: Dados da pesquisa dos autores.

Dentre as características mais marcantes desse filo, além dos pares de apêndices articulados, como mencionado anteriormente, é o resistente exoesqueleto constituído de proteínas e, principalmente, polímero de um carboidrato chamado de quitina (Dias et al., 2013). Esse exoesqueleto ou cutícula, é um dos responsáveis pelo sucesso ecológico do grupo. O exoesqueleto reveste todo o corpo do animal e é formado por placas que se articulam, permitindo os movimentos do corpo e de seus apêndices (Gallo et al., 2002). Por apresentar um aspecto rígido, este atua como uma estrutura de suporte, principalmente para a musculatura interna do corpo e apresenta também função protetora, protegendo a superfície do animal contra a abrasão e ataque de patógenos. Além disso, a cutícula fornece uma barreira efetiva contra gradientes osmóticos e iônicos, e desta forma, é um meio importante de controle homeostático (Barnes et al., 2008). Recobrindo externamente a quitina, há uma camada de cera que torna o exoesqueleto dos artrópodes praticamente impermeável, evitando assim, a perda excessiva de água corporal para o ambiente. Esse fato permitiu a esses animais ocuparem com sucesso o ambiente terrestre, mesmo em regiões áridas (Gullan \& Cranston, 2012; Lopes \& Rosso, 2016).

O exoesqueleto dos artrópodes deve ser substituído, por um processo denominado de ecdise ou muda, para que o animal cresça em tamanho ou aumente o número de segmentos e apêndices (Barnes et al., 2008). Neste processo, o exoesqueleto velho é rompido em pontos de fragilidade e o animal sai dessa espécie de "armadura", a qual é abandonada (Gullan \& Cranston, 2012). 
Desta forma, questionou-se os discentes sobre o crescimento dos artrópodes, se este era contínuo, assim como nos vertebrados. Além disso, pediu-se para que os mesmos justificassem a resposta. Ao realizar a análise do pré-questionário, evidenciou-se respostas bem variadas, entres elas, sim (33\%), não $(29,1 \%)$ e outros não souberam responder (37,5\%) (Figura 4). Após observação dos materiais incrustados e explicações durante a aula, os alunos puderam evidenciar que os artrópodes não apresentam crescimento contínuo, como nos vertebrados, perfazendo um total de $84 \%$ de acertos pós-questionário (Figura 4). Dentre as justificativas, verificou-se as seguintes respostas: "o crescimento dos artrópodes é gradual e necessita da troca do exoesqueleto para permitir seu crescimento", "precisam mudar sua carapaça para poder crescer" e "os artrópodes não crescem continuamente e sim gradualmente, porque antes eles precisam trocar a sua carapaça e esse processo chama-se ecdise".

Figura 4. Resposta dos alunos sobre o crescimento dos artrópodes.

\section{Os artrópodes apresentam crescimento contínuo como nos vertebrados?}

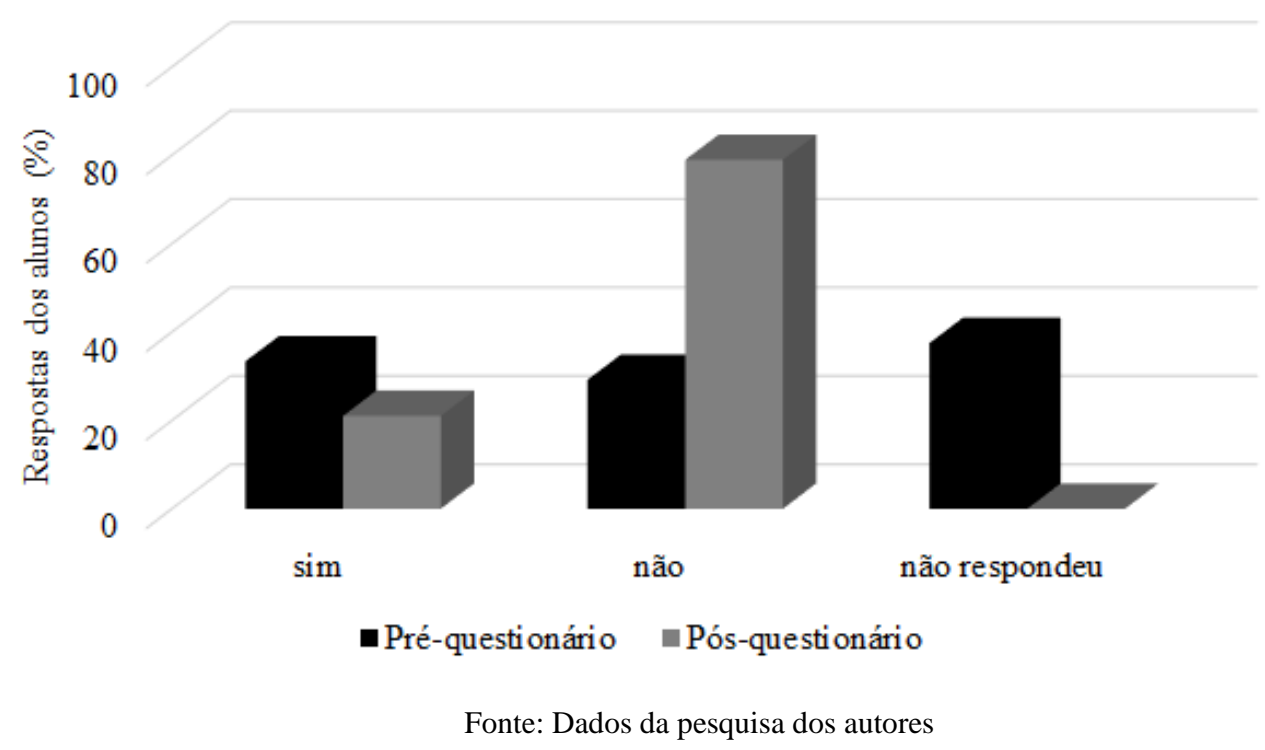

Em princípio, poderíamos imaginar que a existência de um exoesqueleto impediria o crescimento dos artrópodes, mas isso não acontece devido a ocorrência de mudas ou ecdises. O novo exoesqueleto, de início mole, permite um rápido crescimento do animal. Com o tempo, este endurece e cessa o crescimento, que só voltará a ocorrer após a muda seguinte. Enquanto nos vertebrados, de esqueleto interno, o crescimento é gradual, nos artrópodes ocorre "aos saltos", nos intervalos entre as sucessivas mudas. Todo o processo é regulado por ação hormonal, sendo um dos principais, o hormônio da muda, conhecido também como ecdisônio (Gallo et al., 2002).

Na taxonomia desse filo, evidencia-se claramente cinco grupos distintos de artrópodes, os quais reconhecemos como subfilos: Trilobitomorpha (trilobitas e seus parentes, extintos desde o final do Paleozóico), Crustacea (caranguejos, camarões, etc.), Hexapoda (insetos e seus parentes), Myriapoda (lacraias, piolhos-de-cobra e seus parentes) e Cheliceriformes (límulos, aracnídeos, etc.) (Brusca et al., 2018). Dentro do Subfilo Hexapoda (animais que apresentam três pares de pernas), encontramos a classe Insecta, representada por todos os insetos; do latim insectum, significa animal de corpo sulcado, ou separado por anéis, ou seja, segmentado. Estes apresentam como uma das principais características, peças bucais projetadas para fora da cabeça, ou seja, ectógnatos (Triplehorn \& Johnson, 2011). 
A classe Insecta foi uma das escolhidas para serem trabalhadas como ferramenta didática com os alunos, pois são de grande importância para o meio ambiente e para agricultura (polinização, agentes cicladores de nutrientes, inimigos naturais e pragas) (Barnes et al., 2008). Como mencionado anteriormente, os insetos são os animais mais abundantes e diversificados existentes na terra, com aproximadamente 1 milhão de espécies descritas (Bednaski, 2013). Estes fazem parte do cotidiano dos alunos e podem ser encontrados em quase todos os ecossistemas e nos mais diversos ambientes, tais como vegetação rasteira, arbustiva ou arbórea; sobre a superfície da vegetação ou no seu interior; em flores, frutos e folhas; sobre ou sob o solo; em grãos armazenados (Gullan \& Cranston, 2012); no interior de residências; em criação de animais domésticos; em material orgânico em decomposição; focos de iluminação pública, na água, etc. Desta forma, a coleção entomológica incrustada em resina proporciona aprendizado aos alunos por meio do reconhecimento do habitat, tipo de alimentação, características morfológicas e a importância dos diversos grupos de insetos na natureza.

O corpo desses animais passou por várias especializações regionais, ou tagmose, de forma a produzir grupos de segmentos especializados para desempenhar diferentes funções. Essas especializações do corpo (por exemplo, cabeça, tórax e abdome) são denominadas de tagmas (Brusca \& Brusca, 2007). Através de observações das características morfológicas externas, é possível distinguir os diferentes subfilos de artrópodes. Assim sendo, os discentes foram questionados sobre a segmentação corpórea da Classe Insecta. No pré-questionário, as respostas foram variadas sobre este assunto. Destes, 50\% responderam que o corpo dos insetos é dividido em cabeça, tórax e abdome, 33\% em cabeça e tronco, e 8,33\% em cefalotórax e tronco; cefalotórax e abdome; e não tem conhecimento sobre o assunto, respectivamente (Figura 5). Após a observação dos exemplares, os discentes puderam evidenciar com maior clareza que o corpo dos insetos é dividido nas seguintes tágmas: cabeça, tórax e abdome. Desta forma, nesta questão houve 100\% de acertos posteriormente.

Figura 5. Resposta dos alunos sobre Segmentação corpórea da Classe Insecta.

\section{A respeito da segmentação corporal dos insetos pode-se afirmar que a divisão de seus corpos está correta em:}

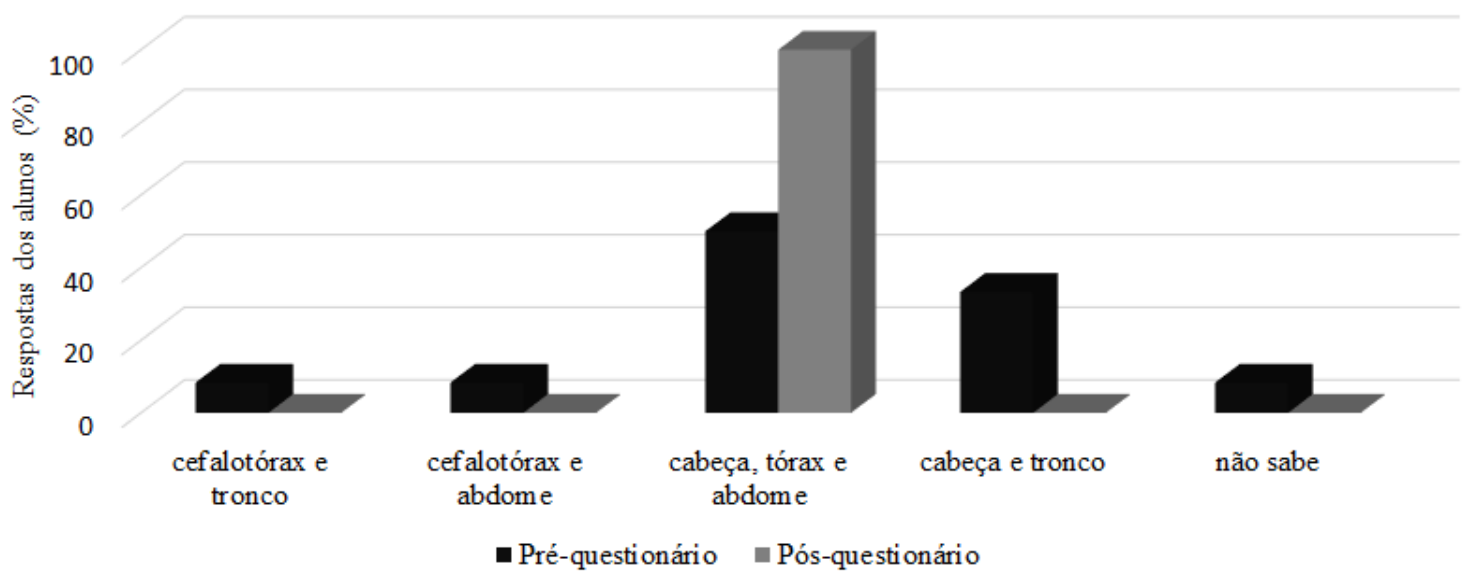

Fonte: Dados da pesquisa dos autores.

A cabeça dos insetos funciona como um centro sensorial, nela é possível evidenciar a presença de apêndices fixos (olhos compostos e ocelos) e os móveis (peças bucais e antenas). O tórax é o centro locomotor, é o local onde se encontram inseridas as pernas e as asas. Além disso, o abdome é uma região altamente especializada que contém principalmente as vísceras (Hickman et al., 2019). 
Com relação ao sistema sensorial dos insetos, um dos mais evidentes são as antenas. Desta forma, os discentes foram questionados se os insetos as possuíam. Todos os entrevistados afirmaram antes e após o questionário que insetos apresentam antenas. No entanto, previamente, grande parte dos alunos não sabiam as funções as quais desempenhavam. Após a aula e observação dos exemplares, estes mencionaram que os insetos apresentam um par de antenas e desempenham principalmente função sensorial.

Segundo Gallo et al. (2002), as antenas são apêndices móveis da cabeça e todos os adultos possuem um par de antenas (díceros). Estas apresentam função sensorial, tais como olfato, audição, tato e gustação e, deste modo apresentam inúmeras modificações e estruturas para desempenhar essas funções. As antenas também podem desempenhar funções de equilíbrio e auxiliar o macho a segurar a fêmea durante a cópula. Além disso, podem ser um caráter de dimorfismo sexual, ou seja, é possível o reconhecimento do sexo de algumas espécies com base nas antenas (Triplehorn \& Johnson, 2011). As mesmas também servem como característica de ordem taxonômica. Com base nas antenas é possível diferenciar, por exemplo, borboletas de mariposas. As borboletas apresentam uma antena clavada, ou seja, termina em uma dilatação semelhante à uma clava (massa apical), enquanto as mariposas apresentam antenas de outro tipo.

Segundo Gallo et al. (2002), as pernas são apêndices locomotores dos insetos que vivem em ambiente terrestre ou aquático. Os insetos adultos apresentam 3 pares de pernas (hexápodes) e um número variável nos imaturos (larvas ou lagartas). Além da locomoção, as pernas são adaptadas às mais diversas funções, tais como andar, correr, cavar o solo, coletar alimentos, capturar presas, etc. Com relação a morfologia externa dos insetos, foi questionado quantos pares de pernas os mesmos possuem. Os discentes responderam no pré-questionário, em sua maioria, que os insetos apresentam quatro pares de pernas (66\%) (Figura 6). Alguns responderam dois (25\%) ou três pares de pernas (8,33\%). Após a observação dos insetos incrustados, os alunos de forma geral entenderam que os mesmos apresentam 3 pares de pernas, perfazendo um total de 92,3\% de acertos (Figura 6).

Figura 6. Resposta dos alunos sobre o número de pernas presentes na Classe Insecta.

\section{Os insetos possuem quantos pares de pernas?}

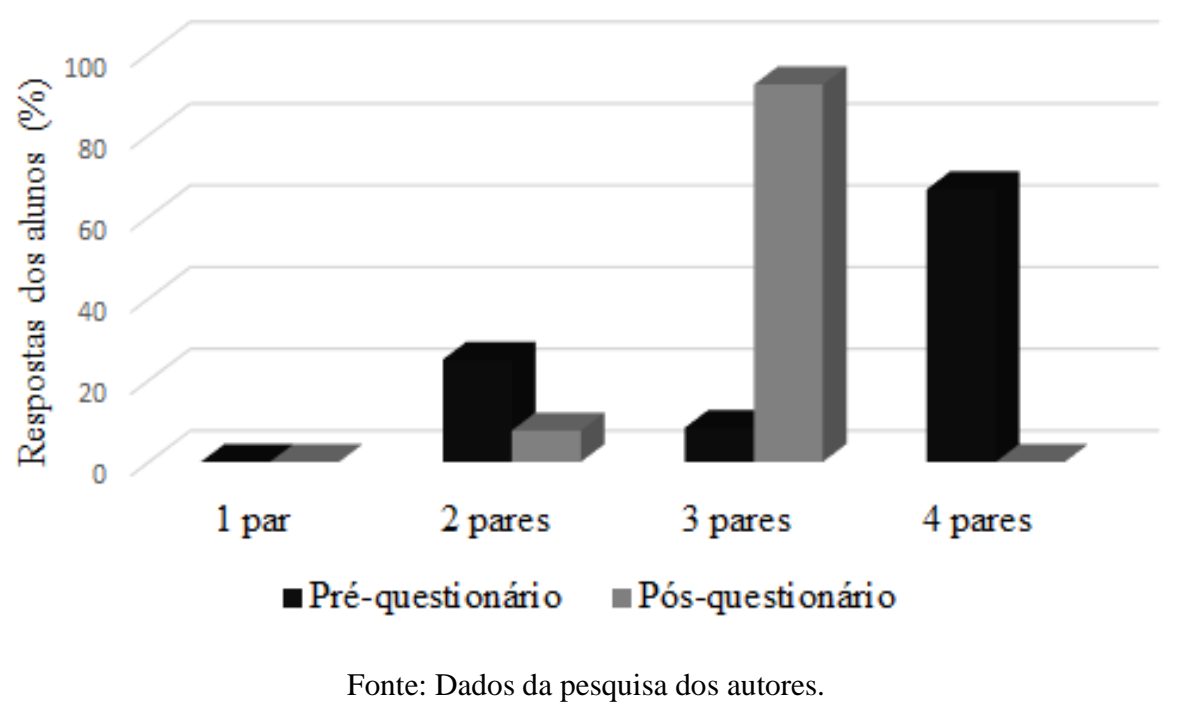

Conforme a função a ser exercida, as pernas podem apresentar modificações em suas partes que as tornam mais adaptadas para o desempenho daquela função. Essas modificações são adaptações dos insetos de acordo com o meio onde vivem e podem ocorrer nos três pares de pernas ou somente no primeiro ou último par. Um dos insetos mais comuns na vida cotidiana dos discentes são as abelhas. Nelas é possível verificar que as pernas são do tipo coletora, pois servem para recolher e 
transportar os grãos de pólen. Estas apresentam uma espécie de "cesto", chamado de corbícula para desempenhar tal função. No caso, se refere ao terceiro par de pernas das abelhas (Gallo et al., 2002).

O grande sucesso desse grupo no meio terrestre pode ser atribuído, como mencionado anteriormente, ao seu exoesqueleto quitinoso e à evolução do voo. Tal característica permitiu que os insetos se deslocassem com maior eficiência e agilidade, principalmente na fuga contra predadores e na busca de novas fontes de alimento ou de locais com condições mais adequadas à sua sobrevivência (exploração de novos hábitats). Os insetos são os únicos invertebrados com adaptação ao voo (Brusca et al., 2018; Triplehorn \& Johnson, 2011). Em outros grupos, houve perda secundária das asas associadas, principalmente, à vida ectoparasitária, como piolhos e pulgas. E também à vida subterrânea, como nos soldados e operários de cupins e deste último em formigas (Lopes \& Rosso, 2016). Nas formigas cortadeiras, por exemplo, as asas só se desenvolvem na época de reprodução. Após a revoada para o acasalamento, perdem as asas e cavam a terra para fundar um ninho, se instalando em diferentes locais (Silva et al., 2016).

Ainda falando sobre o centro locomotor dos insetos, questionou-se quantas asas eles possuem e qual a função das mesmas. No pré-questionário, a maior parte dos discente responderam que os insetos apresentam dois pares de asas funcionais (58,33\%), $25 \%$ dos entrevistados responderam todas as alternativas corretas, ou seja, podem possuir um par, dois pares ou nenhum par de asas funcionais e 16,66\% responderam apenas 1 par de asas funcionais (Figura 7). Após a demonstração dos exemplares incrustados e uma aula expositiva dialogada, os alunos verificaram que existe uma diversidade bastante grande de insetos na natureza e estes podem apresentar número variado de asas, ou podem não as possuir. Desta forma, estes verificaram que todas as alternativas estavam corretas, perfazendo um total de 84,61\% de acertos posteriormente (Figura 7). Sobre a função das asas, os alunos mencionaram que estas possuem: "Capacidade de voo e exploração de novos ambientes", "função locomotora" e "As asas auxiliam na procura de um parceiro sexual durante época de acasalamento".

Figura 7. Resposta dos alunos sobre o número de asas funcionais presentes na Classe Insecta.

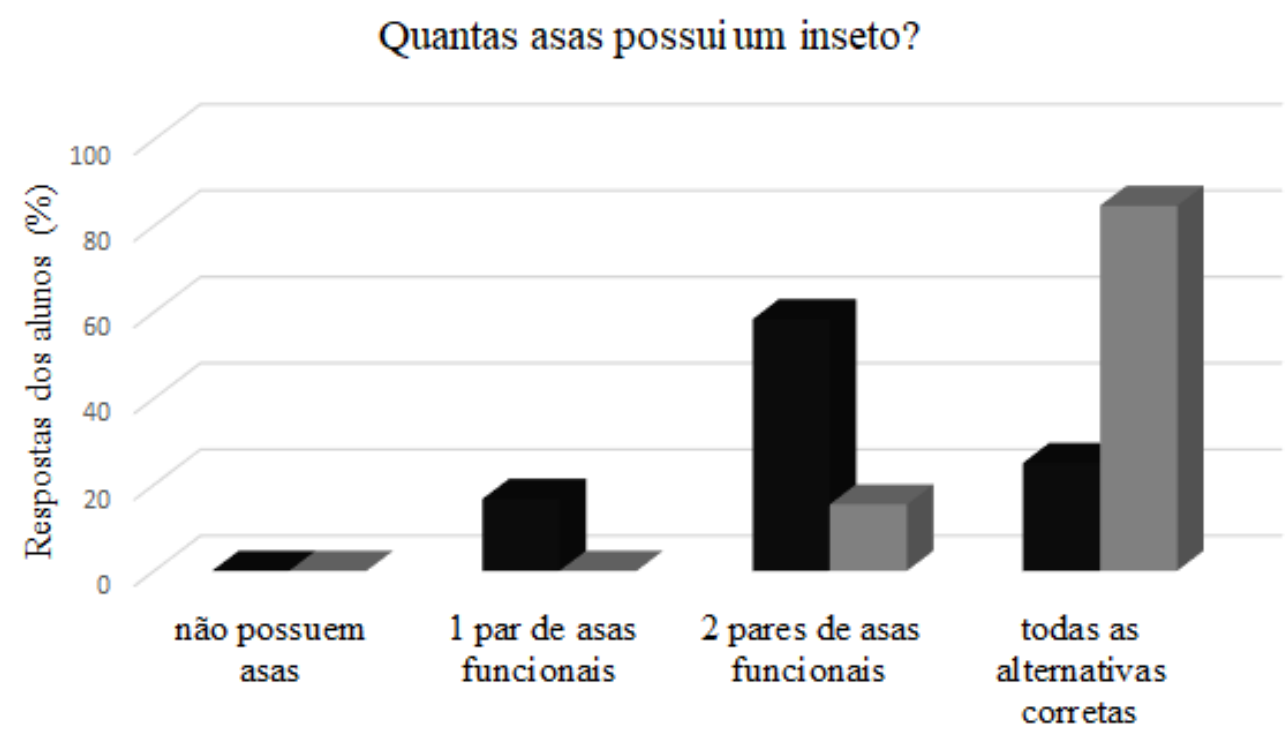

- Pré-questionário $\quad$ Pós-questionário

Fonte: Dados da pesquisa dos autores.

Segundo Gallo et al. (2002), a constatação de insetos primitivos sem asas, semelhante às traças-dos-livros, implica na suposição de que as asas evoluíram após o aparecimento dos insetos. No decorrer do processo de evolução do grupo, as primeiras asas eram rígidas, em número de quatro (um par anterior e outro par posterior) e se dispunham perpendicularmente 
em relação ao eixo longitudinal do corpo, como nas libélulas atuais, ou seja, não se dobravam em repouso (Lopes \& Rosso, 2016). Em razão de muitas modificações na região de articulação da asa com o tórax, as asas dobravam-se sobre o corpo do inseto em repouso. Isso permitiu que os insetos se refugiassem em locais estreitos (Gallo et al., 2002).

As asas variam muito em tamanho, espessura e cor. As mais comuns são as membranosas, que são finas e transparentes, encontradas por exemplo, em moscas, mosquitos e libélulas. As asas anteriores das baratas e dos gafanhotos são um pouco mais espessas, pergamináceas, cobrindo e protegendo o segundo par, o qual é membranoso. O primeiro par de asas dos besouros, é chamado de élitro, é bem duro, resistente e opaco; e não tem função de voo. Os élitros têm função de proteger os animais e se abrem para permitir a livre movimentação do segundo par de asas, o qual é membranoso e utilizado para voo (Silva et al., 2016).

Os discentes foram questionados sobre estruturas presentes no abdome dos insetos, tais como a presença de estilos e/ou cercos, e espiráculos. Nesta questão, o intuito era saber se os estudantes sabiam previamente a função destas estruturas. Ao analisar o conhecimento prévio dos alunos, observou-se que estes não conheciam tais estruturas. Após a aula expositiva dialogada e observação dos exemplares incrustados, os discentes mencionaram que os cercos e estilos apresentam função sensorial. Os cercos podem auxiliar na cópula e defesa contra predadores e os espiráculos servem de porta de entrada do oxigênio.

$\mathrm{O}$ abdome dos insetos não tem apêndices, é o local onde encontram-se a maior parte das vísceras. Este pode apresentar, na região terminal, o ovipositor, para a postura de ovos e é também nessa região do corpo que se localiza o ferrão das abelhas e vespas, um ovipositor modificado para a injeção de veneno. Lateralmente, em cada segmento do abdome percebem-se pequenas pontuações, denominadas de estigmas ou espiráculos, que são as aberturas dos órgãos respiratórios (BRUSCA et al., 2018). Alguns insetos podem apresentar cercos, que são apêndices abdominais pares, multissegmentados ou não, localizados no último segmento do abdome. Sua principal função é sensorial, mas podem auxiliar na cópula e até exercer função preensora, como no caso dos insetos chamados de tesourinhas (Gallo et al., 2002). São encontrados também em traçasdos-livros, louva-a-deus, baratas. Pode haver também os estilos, multissegmentado, e mais curtos do que os cercos, com função sensorial e presentes apenas nos machos, como baratas, sendo um caráter de dimorfismo sexual. Além destas estruturas mencionadas, os pulgões podem apresentar um par de apêndices dorsais, denominados de sifúnculos ou cornículos, os quais podem liberar feromônio de alarme (Fujihara et al., 2011).

\section{Considerações Finais}

Levando em consideração e valorizando a base de conhecimentos teóricos prévios dos discentes, a aplicação da coleção didática com os insetos incrustados na aula ministrada, permitiu a manipulação dos materiais e uma análise detalhada das características morfológicas dos exemplares, contribuindo para a construção de conhecimentos de forma prática, lúdica e atrativa. Com isso, os alunos conseguiram observar com maior clareza e assimilar algumas espécies dos animais que são parte do seu cotidiano, realizando o reconhecimento dos diferentes espécimes, do habitat, tipo de alimentação, características morfológicas e da importância e função chave dos diversos grupos de insetos na natureza.

Com base na análise dos dados, constatou-se resultado satisfatório pós questionário, que foi aplicado após a aula e o manuseio dos materiais didáticos, apresentando um maior número de respostas corretas em relação ao primeiro questionário. Assim, estes resultados demonstram que, a técnica de incrustação foi significativa no processo de ensino-aprendizagem dos alunos e que, os mesmos, de fato adquiriram o conhecimento desejado acerca do conteúdo enfatizado, atingindo assim, os objetivos propostos e validando a efetividade da aula ministrada e, consequentemente, a efetividade da implantação de metodologias ativas e inovadoras de aprendizagem em sala de aula. 
Conhecendo as dificuldades que as escolas estaduais muitas vezes apresentam em desenvolverem aulas práticas, seja por falta de infraestrutura ou recursos materiais que contribuam com o processo de ensino-aprendizagem. A oferta de um material didático de fácil confecção, resistente e permanente como os incrustados em resina, pode ser um facilitador do aprendizado de forma diferenciada, interativa e dinâmica aos alunos do Ensino Médio da Escola Estadual Dr. Guilherme Jose Missen.

Além dos materiais produzidos, outros artrópodes futuramente poderão ser preparados, tais como miriápodes (piolhode-cobra, lacraia), aracnídeos (aranhas, opiliões, escorpiões, pseudoescorpião) e crustáceos (caranguejo, camarão). Estes materiais poderão ser explorados e visualizados pela comunidade externa em feira de ciências, amostras científicas, semanas acadêmicas, entre outras atividades.

\section{Referências}

Amorim, A. D. S. (2013). A influência do uso de jogos e modelos didáticos no ensino de biologia para alunos de ensino médio. Monografia) Universidade Estadual do Ceará-UECE, Universidade Aberta do Brasil-UAB. Centro De Ciências e Saúde-CCS, Curso de Licenciatura em Ciências Biológicas. BeberibeCeará.

Barnes, R. S. K., Calow, P., Olive, P. J. W., Golding, D. W., \& Spicer, J. I. (2008). Os invertebrados: uma síntese. Atheneu.

Bednaski, A. V. Revisão bibliográfica: hemolinfa de artrópodes com ênfase em aranhas, escorpiões e insetos venenosos.

Berbel, N. A. N. (2011). As metodologias ativas e a promoção da autonomia de estudantes. Semina: Ciências sociais e humanas, 32(1), 25-40.

Brusca, RC, \& Brusca, GJ (2007). Invertebrados (Vol. 2). Guanabara Koogan S.A.

Brusca, R. C.; Moore, W.; Sshuster, S. M. (2018). Invertebrados (3a ed). Guanabara Koogan S.A.

Capanga, P. X. A. A.; Silva da, F. M.; Ianuzzi, L. (2013) Aspectos da preservação de insetos em resina para coleções didáticas. $65^{\text {a }}$ Reunião Anual da SBPC. http://www.sbpcnet.org.br/livro/65ra/resumos/resumos/5728.htm.

Catani, A., Carvalho, E. G., Santos, F. S. D., Aguilar, J. B. V., \& Campos, S. H. M. A. (2016). Ser Protagonista: Biologia-1º ano ensino médio. Edições SM, $3^{\circ}$ edição.

Dias, K. B., Silva, D. D., Ferreira, L. A., Fidelis, R. R., Costa, J. D. L., Silva, A. D., \& Scheidt, G. N. (2013). Chitin and chitosan: characteristics, uses and production current perspectives. Journal of Biotechnology, 4(3), 184-191.

Diesel, A., Baldez, A. L. S., \& Martins, S. N. (2017). Os princípios das metodologias ativas de ensino: uma abordagem teórica. Revista Thema, 14(1), 268288 .

Fujihara, R. T., Forti, L. C., Almeida, M. D., \& Baldin, E. L. L. (2011). Insetos de importância econômica: guia ilustrado para identificação de famílias. Botucatu, SP: Fundação de Estudos e Pesquisas Agrícolas e Florestais.

Gallo, D., Nakano, O., Silveira Neto, S., Carvalho, R. P. L., Baptista, G. C. de, Berti Filho, E., et al. (2002). Entomologia agricola. FEALQ.

Gullan, P. J., Cranston, P. S., McInnes, K. H., \& Hoenen, S. M. M. (2012). Os insetos: um resumo de entomologia. Roca.

Hickman, C. P., Roberts, L. S., \& Keen, S. L. (2019). Princípios integrados de zoologia. Grupo Gen-Guanabara Koogan.

Lopes, S.; Rosso, S. (2016) Bio. (3a ed.). Saraiva.

Morán, J. (2015). Mudando a educação com metodologias ativas. Coleção mídias contemporâneas. Convergências midiáticas, educação e cidadania: aproximações jovens, 2(1), 15-33.

Paiva, M. R. F., Parente, J. R. F., Brandão, I. R., \& Queiroz, A. H. B. (2016). Metodologias ativas de ensino-aprendizagem: revisão integrativa. SANARERevista de Políticas Públicas, 15(2).

Ruppert, E. E., Fox, R. S., \& Barnes, R. D. (2005). Zoologia dos invertebrados: uma abordagem funcional-evolutiva. In Zoologia dos invertebrados: uma abordagem funcional-evolutiva (pp. 1045-1045).

Santos, N. T., Santos Júnior, I. M., Pereira, G. A. F. (2021). Metodologias ativas na educação profissional e tecnológica: breve teorização. Research, Society and Development, 10(10), 1-8.

Silva, C. da, Jr. et al. (2016). Biologia 3: ensino médio (11a ed.). Saraiva.

Souza Junior, E. M., Sena, J. L., Santana, J. C. F., Arruda, E. B., Ferreira, M. A. S. (2017). Incrustação de insetos em resina para coleções didáticas. Holos, 33 (5), 151-157.

Triplehorn, C. A., \& Johnson, N. F. (2011). Estudo dos insetos. São Paulo: Cengage Learning, 7. 